\title{
CRITICAL CARE
}

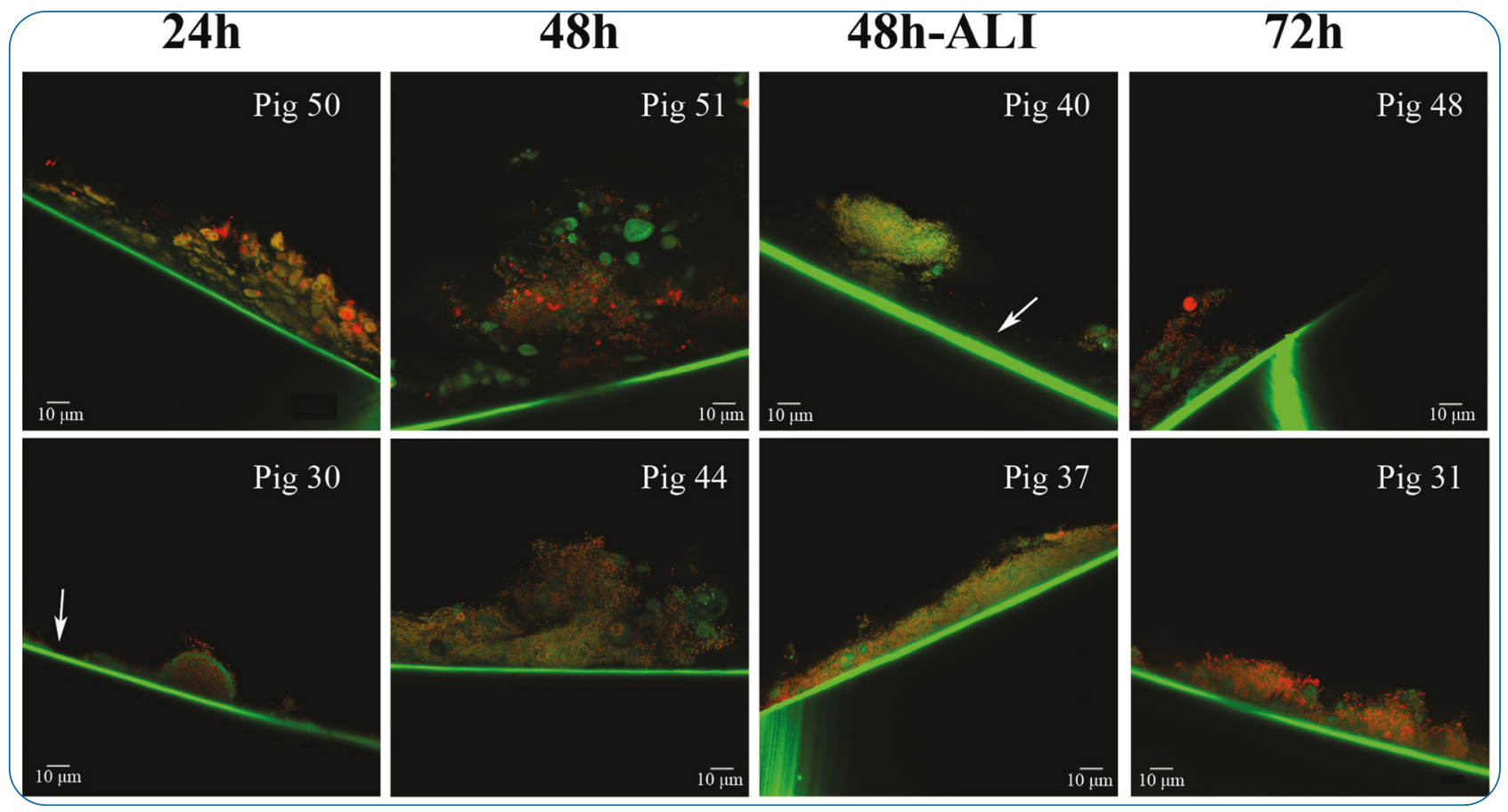

Endotracheal tube biofilm translocation in the lateral Trendelenburg position

Li Bassi et al. 


\title{
Endotracheal tube biofilm translocation in the lateral Trendelenburg position
}

\author{
Gianluigi Li Bassi ${ }^{1,2,3+}$, Laia Fernandez-Barat ${ }^{1,3 \dagger}$, Lina Saucedo ${ }^{1,3}$, Valeria Giunta ${ }^{4}$, Joan Daniel Marti ${ }^{1,3}$, \\ Otavio Tavares Ranzani ${ }^{1,3,5}$, Eli Aguilera Xiol ${ }^{1,3}$, Montserrat Rigol 1,2,3, Ignasi Roca $^{6}$, Laura Muñoz ${ }^{6}$, Nestor Luque ${ }^{1}$, \\ Mariano Esperatti ${ }^{1}$, Maria Adela Saco ${ }^{7}$, Jose Ramirez ${ }^{7}$, Jordi Vila ${ }^{6,8}$, Miguel Ferrer ${ }^{1,2,3}$ and Antoni Torres ${ }^{1,2,3,8^{*}}$
}

\begin{abstract}
Introduction: Laboratory studies demonstrated that the lateral Trendelenburg position (LTP) is superior to the semirecumbent position (SRP) in the prevention of ventilator-associated pulmonary infections. We assessed whether the LTP could also prevent pulmonary colonization and infections caused by an endotracheal tube (ETT) biofilm.

Methods: Eighteen pigs were intubated with ETTs colonized by Pseudomonas aeruginosa biofilm. Pigs were positioned in LTP and randomized to be on mechanical ventilatin (MV) up to 24 hour, 48 hour, 48 hour with acute lung injury (ALI) by oleic acid and 72 hour. Bacteriologic and microscopy studies confirmed presence of biofilm within the ETT. Upon autopsy, samples from the proximal and distal airways were excised for P.aeruginosa quantification. Ventilator-associated tracheobronchitis (VAT) was confirmed by bronchial tissue culture $\geq 3$ log colony forming units per gram (cfu/g). In pulmonary lobes with gross findings of pneumonia, ventilator-associated pneumonia (VAP) was confirmed by lung tissue culture $\geq 3 \log \mathrm{cfu} / \mathrm{g}$.
\end{abstract}

Results: P.aeruginosa colonized the internal lumen of 16 out of 18 ETTs (88.89\%), and a mature biofilm was consistently present. P.aeruginosa colonization did not differ among groups, and was found in $23.6 \%$ of samples from the proximal airways, and in $7.1 \%$ from the distal bronchi $(P=0.001)$. Animals of the 24 hour group never developed respiratory infections, whereas 20\%,60\% and 25\% of the animals in group 48 hour, 48 hour-ALI and 72 hour developed P.aeruginosa VAT, respectively $(P=0.327)$. Nevertheless, VAP never developed.

Conclusions: Our findings imply that during the course of invasive MV up to 72 hour, an ETT P.aeruginosa biofilm hastily colonizes the respiratory tract. Yet, the LTP compartmentalizes colonization and infection within the proximal airways and VAP never develops.

\section{Introduction}

Critically ill, intubated patients are commonly kept in the semirecumbent position to prevent the gastropulmonary route of endogenous colonization [1] and ventilator-associated pneumonia (VAP) [2]. In recent years, consistent data from laboratory studies [3-5] have suggested that the lateral Trendelenburg position (LTP) might be superior to the semirecumbent position in the prevention of VAP. In the LTP, the trachea is oriented

\footnotetext{
* Correspondence: atorres@clinic.ub.es

${ }^{\dagger}$ Equal contributors

'Pulmonary and Critical Care Unit, Hospital Clínic, Calle Villarroel 170, Esc 6/8 Planta 2, 08036 Barcelona, Spain

${ }^{2}$ Institut d'Investigacions Biomèdiques August Pi i Sunyer (IDIBAPS),

Barcelona, Spain

Full list of author information is available at the end of the article
}

below horizontal; thus, aspiration of bacteria-laden oropharyngeal secretions across the endotracheal tube (ETT) cuff is averted $[4,5]$. Additionally, in such a position the mucus clearance rate is strongly enhanced $[3,6]$. Currently, a multicenter clinical trial is testing in critically ill patients the efficacy, safety and feasibility of the LTP in the prevention of VAP (available from ClinicalTrials.gov, NLM Identifier: NCT01138540).

Nevertheless, during invasive mechanical ventilation (MV), aspiration of oropharyngeal pathogens is not the only pathogenic mechanism for the development of VAP. In particular, the ETT is commonly made of polyvinylchloride and some bacterial species avidly adhere to polyvinylchloride and form biofilm $[7,8]$. Bacteria organized into this defensive milieu are shielded by antibiotics 
[9] and circumvent the host immune response [10]. ETT biofilm has been consistently associated with VAP [11-14]. Indeed, in the majority of patients who developed VAP, Adair et al. [13] found a strict association between pathogens cultured from the ETT biofilm and the lower respiratory tract. More recently Wilson et al. [15] found that mature biofilm (stage III/IV) was associated with the development of VAP.

Importantly, the role of the LTP in the prevention of pulmonary colonization and infections caused by ETT biofilm is yet to be investigated. Thus, we set out to examine the dynamics of pulmonary colonization by ETT Pseudomonas aeruginosa biofilm in animals positioned in the LTP. In particular, we evaluated whether the time on MV increased the risk of bronchial colonization and pulmonary infections, and whether translocation of pathogens from ETT biofilm and the development of pulmonary infections could be facilitated by concomitant lung injury.

\section{Materials and methods}

The Institutional Ethics Committee approved the protocol, as fully detailed in the acknowledgment section. Animals were managed according to the National Institutes of Health guidelines for the use and care of animals [16].

\section{ETT $P$. aeruginosa biofilm}

ETTs colonized by $P$. aeruginosa biofilm were obtained from a previous study [5]. During this associated study, animals were challenged twice with $5 \mathrm{~mL}$ of $10^{7}$ to $10^{8}$ colony forming units (cfu)/mL of a log-phase culture of P.aeruginosa into the oropharynx. We employed a respiratory isolate of ceftriaxone-resistant, biofilm-producer P.aeruginosa, derived from P.aeruginosa ATCC 27853. Following bacterial challenge, pigs were ventilated for 66 hours to allow substantial colonization of the ETT by P.aeruginosa, and biofilm formation [17]. Prior to the autopsy, secretions within the ETT were aspirated and plated on MacConkey media to identify Gram-negative aerobic bacteria and quantification of P.aeruginosa. Upon extubation, the ETT was placed in a sealed specimen bag and stored at $-80^{\circ} \mathrm{C}$. Finally, prior to its use in the current study, the ETT was stored during a 24-hour period at $-4^{\circ} \mathrm{C}$ for slow thawing.

\section{Animal preparation and handling}

Eighteen pigs (weight $31.5 \pm 2.12 \mathrm{Kg}$; range 29 to $36 \mathrm{Kg}$ ) were induced [18], intubated with the aforementioned ETTs and connected to a mechanical ventilator (SERVO-I, Maquet, Fairfield, NJ USA). Internal ETT cuff pressure was maintained at $28 \mathrm{~cm} \mathrm{H}_{2} 0$ through a mechanical device [19]. Anesthesia was maintained with a continuous infusion of midazolam, 0.2 to $0.8 \mathrm{mg} / \mathrm{Kg} / \mathrm{h}$, and fentanyl 5 to $10 \mu \mathrm{g} / \mathrm{Kg} / \mathrm{h}$, in order to maintain cessation of spontaneous movements, following painful stimulation. Pigs were ventilated in volume-control, square-wave inspiratory flow, inspiratory fraction of oxygen of $40 \%$, duty cycle of 0.25 , tidal volume $8 \mathrm{~mL} / \mathrm{Kg}$, without positive end-expiratory pressure (PEEP), and respiratory rate adjusted to maintain $\mathrm{Pa}_{\mathrm{CO} 2}$ within the physiologic range. Inspiratory gases were conditioned through a heated humidifier (Conchatherm III, Hudson RCI, Temecula, CA, USA). Throughout the study, $50 \mathrm{mg} / \mathrm{Kg}$ of ceftriaxone was administered every 12 hours to prevent pulmonary colonization by endogenous pathogens. Endotracheal suctioning was performed every 6 hours or when clinically indicated. Importantly, saline was never instilled into the airways throughout the suction procedure. Quality of mucus (normal or purulent) was recorded. Body temperature and white blood cells count were assessed every 12 hours.

\section{Randomization}

Following surgical preparation, pigs were placed in the lateral position with a slight Trendelenburg $\left(-5^{\circ}\right)$. Then, pigs were randomized into the following groups: 1) group $24 \mathrm{~h}$ : on MV for 24 hours; 2) group $48 \mathrm{~h}$ : on MV for 48 hours; 3) group $48 \mathrm{~h}$ /acute lung injury (ALI): in an additional group on MV for 48 hours, ALI was induced as previously reported [20]. Briefly, $0.08 \mathrm{ml} / \mathrm{Kg}$ of oleic acid (Sigma-Aldrich, St Louis, MO, USA) emulsified into $18 \mathrm{~mL}$ of blood was slowly injected into the right atrium. To produce uniform injury, the total dose of oleic acid-blood solution was partitioned into three equal aliquot portions, which were sequentially injected into the distal port of the central venous catheter with the pig in three positions: prone, right lateral, and left lateral; group $72 \mathrm{~h}$ : on MV for 72 hours.

\section{Respiratory measurements}

Ventilatory settings were evaluated every 6 hours and adjusted to maintain blood gases within the physiologic range. Respiratory mechanics were measured daily, as previously reported [21]. Following the assessment of pulmonary variables, arterial gas exchanges were evaluated.

\section{Autopsy, microbiological studies and ventilator-associated tracheobronchitis (VAT)/VAP definitions}

Upon autopsy, we took four tissue samples from the proximal airways and seven samples from segmental bronchi (Figure 1). Tissue samples were plated on MacConkey agar and incubated aerobically for 48 hours at $37^{\circ} \mathrm{C}$. Finally, bacterial growth was counted and pathogens identified by mass spectrometry through a Microflex LT (BrukerDaltonics $\mathrm{GmbH}$, Leipzig, Germany), and bacterial identification was performed using the MALDI BioTyper 2.0 software (BrukerDaltonics). This system measures 


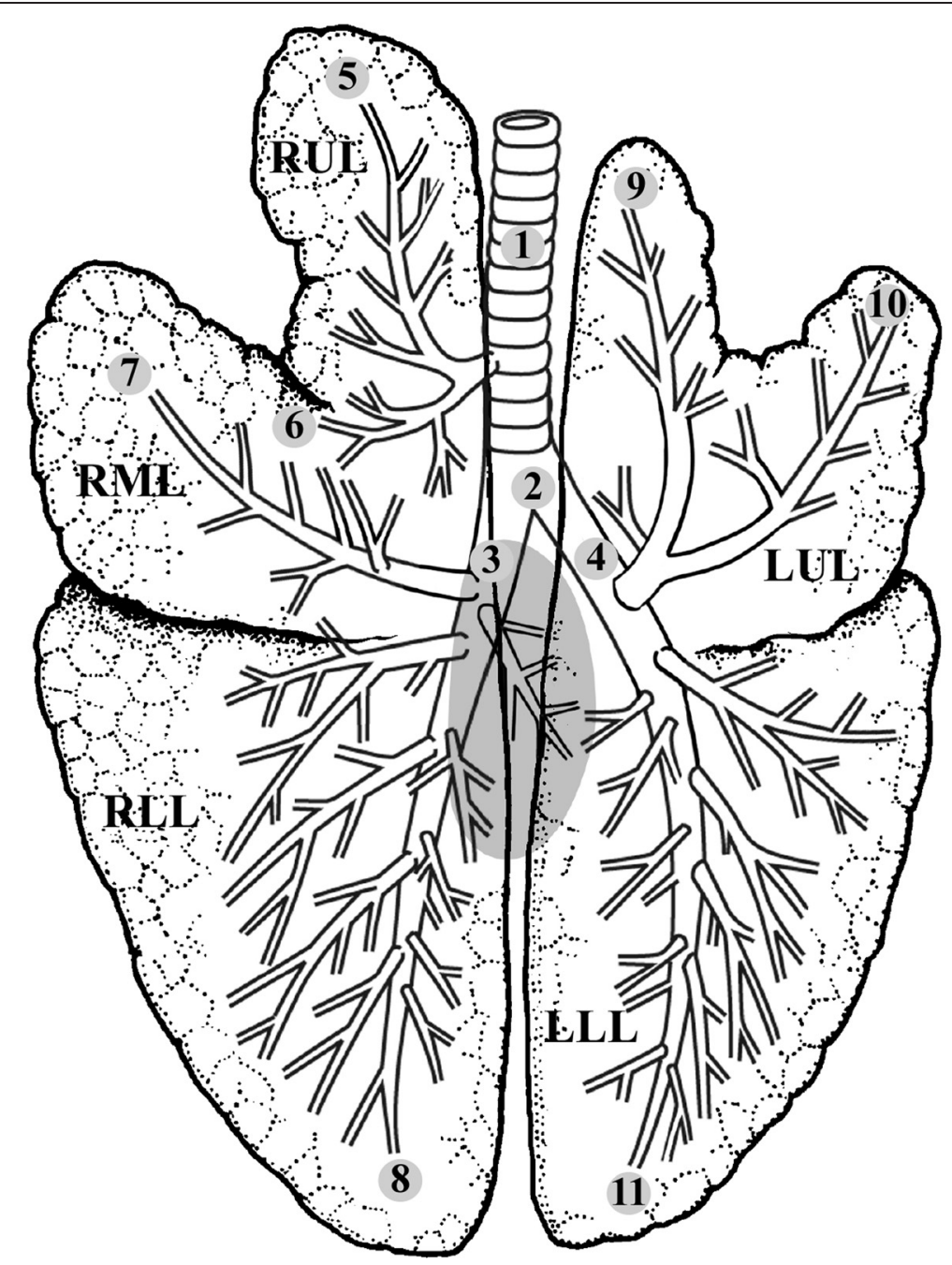

Figure 1 Bronchopulmonary anatomy of the pig lung. The numbers from 1 to 11 indicate sites from which samples were taken for microbiological studies: 1 to 2, trachea; 3 to 4, main bronchi; 5 to 11, segmental bronchi. RUL, right upper lobe; RML, right medium lobe; RLL, right lower lobe; LUL, left upper lobe; LLL, left lower lobe.

highly abundant bacterial proteins. The characteristic patterns of these proteins are used to identify a particular microorganism by matching the respective protein spectrum with an extensive database [22]. Pulmonary infections were clinically suspected in case at least two of the following clinical features were present at the end of the study: body temperature $>38.5^{\circ} \mathrm{C}$ or $<36^{\circ} \mathrm{C}$; white blood count $>14,000 / \mathrm{mm}^{3}$ or $<4000 / \mathrm{mm}^{3}$ and purulent secretions. VAT was microbiologically confirmed when at least one bronchial tissue culture was $\geq 3 \log$ $\mathrm{cfu} / \mathrm{g}$. Additionally upon autopsy pulmonary lobes with any apparent gross finding of pneumonia (edematous tissue, areas of consolidation, mucopurulent material in the tracheobronchial tree, abscess) were sampled. Importantly, in group 48-ALI, all lobes were sampled due to the extensive pulmonary injury, irrespective of gross findings of pneumonia. VAP was microbiologically confirmed according to a quantitative lobar bacterial culture $\geq 3 \log \mathrm{cfu} / \mathrm{g}[23,24]$.

\section{ETT microbiological studies}

Upon extubation, the ETT was sealed with clamps placed at the proximal and distal tips. The external surface was cleaned with sterile gauzes and decontaminated through careful rinsing with $80 \%$ alcohol and saline solutions. Then, the ETT was longitudinally cut open, and a $3-\mathrm{cm}-$ long section of the dependent half was dissected to quantify Gram-negative and Gram-positive aerobic pathogens as previously reported [25]. In two animals of each study group, two 1-cm-long hemi-sections of the ETT were dissected to visually confirm presence of ETT biofilm through confocal scanning laser microscopy (CSLM) [26] and scanning electron microscopy (SEM) [25]. Biofilm 
stage was assessed through SEM micrographs analysis, as previously described [15].

\section{Statistical analysis}

To the best of our knowledge, only one study [17] in dogs that were challenged with P.aeruginosa in the oropharynx has assessed the role of ETT biofilm on pulmonary colonization. Based on these limited data, we assumed a mean P.aeruginosa bronchial burden in group $24 \mathrm{~h}, 48 \mathrm{~h}, 48$-ALI and $72 \mathrm{~h}$ of $2,3,5$ and $4 \mathrm{log} \mathrm{cfu} / \mathrm{g}$, respectively, and a standard deviation of $0.5 \mathrm{log} \mathrm{cfu} / \mathrm{g}$ for each group. Thus, we calculated that approximately three animals should have been included in each group to detect statistically significant differences for a statistical power of $90 \%$ and type 1 bias of $5 \%$. Parametric and nonparametric analyses were used in accordance with the results of the Shapiro-Wilk $W$-test. One-way analysis of variance (ANOVA) or the Kruskal-Wallis test with post-hoc Student's $t$-test or Wilcoxon Mann-Whitney test and Bonferroni correction, was employed to analyze continuous variables. The paired $t$-test and Wilcoxon signed ranks test were used to detect differences between paired measurements. Categorical variables were analyzed using the chi-square and Fisher's exact test. Of note, only animals with ETTs colonized by P.aeruginosa were included in the analysis of tracheobronchial colonization by P.aeruginosa. In post-hoc analyses, linear regression and the Wilcoxon Mann-Whitney tests were used to assess the effects of length of stay on MV and lung injury on P.aeruginosa lung burden. A two-sided $P$ value $<0.05$ was considered statistically significant. All analyses were performed using SAS 9.2 software.

\section{Results}

\section{Study animals}

Four animals were included in the $24 \mathrm{~h}$ and $72 \mathrm{~h}$ group, whereas, five were included in the $48 \mathrm{~h}$ and $48 \mathrm{~h} / \mathrm{ALI}$ groups. Seventeen out of eighteen animals completed the study, one animal in the $48 \mathrm{~h}$-ALI group died after 18 hours due to severe respiratory instability.

\section{Endotracheal tube colonization}

Prior to the current study, ETTs were frozen for $60.7 \pm 21.5$ days in group $24 \mathrm{~h} ; 47.6 \pm 41.3$ in group $48 \mathrm{~h}$; $44.8 \pm 33.4$ in group $48 \mathrm{~h}$-ALI and $58.2 \pm 38.9$ in group $72 \mathrm{~h}(P=0.879)$. Upon completion of the previous study, the secretions collected from the ETT inner lumen in groups $24 \mathrm{~h}, 48 \mathrm{~h}$ and $72 \mathrm{~h}$ were always colonized by $P$. aeruginosa at a mean concentration of $5.89 \pm 0.95 \log$ $\mathrm{cfu} / \mathrm{mL}$ without differences among groups $(P=0.983)$. Amid other Gram-negative pathogens, secretions were colonized by Escherichia coli in three ETTs (13.04\%), Bordetella pertussis and Klebsiella pneumonia were found in one ETT each (4.35\%).
In the current study, upon extubation P.aeruginosa colonized the ETT internal lumen of 16 out of 18 ETTs $(88.89 \%)$, at a mean concentration of $6.94 \pm 0.77$, $6.85 \pm 1.14, \quad 8.60 \pm 0.69$ and $8.21 \pm 1.04 \log \mathrm{cfu} / \mathrm{mL}$ in group $24 \mathrm{~h}, 48 \mathrm{~h}, 48 \mathrm{~h}$-ALI and $72 \mathrm{~h}$, respectively $(P=0.050)$. P.aeruginosa was not found in only one ETT of group $24 \mathrm{~h}$, which was instead colonized by Proteus vulgaris $(7.85 \log \mathrm{cfu} / \mathrm{mL})$ and E.coli $(7.85 \log$ $\mathrm{cfu} / \mathrm{mL}$ ); whereas, in one ETT of group 48-ALI the internal surface was only colonized by Staphylococcus aureus and Bordetella bronchiseptica at a concentration of 6.41 and $4.40 \log \mathrm{cfu} / \mathrm{mL}$, respectively. Among the ETTs colonized by P.aeruginosa, the number of days in storage was not associated with ETT colonization burden $(\mathrm{N}: 16, r$-square $=0.05, P=0.386)$. In Figure 2 we report all pathogens cultured from the ETT inner lumen. Gramnegative pathogens accounted for $83.67 \%$ of the isolates, whereas $16.33 \%$ were Gram-positive. S. aureus were the most frequent Gram-positive bacteria. As clearly shown in Figures 3 and 4, stage III/IV biofilm was consistently present in all analyzed ETTs.

Ventilatory management, airflows and pulmonary mechanics Endotracheal suctioning was performed $5.2 \pm 0.5,4.5 \pm$ $0.5,5.0 \pm 1.1,4.3 \pm 0.5$ times per day in groups $24 \mathrm{~h}, 48 \mathrm{~h}$, $48 \mathrm{~h}$-ALI, $72 \mathrm{~h}$, respectively $(P=0.100)$. As expected, in group $48 \mathrm{~h}$-ALI, following oleic acid instillation the respiratory system elastance increased from $45.4 \pm 4.0$ to $75.0 \pm 9.6 \mathrm{~cm} \mathrm{H}_{2} \mathrm{O} / \mathrm{L}(P=0.002)$ and the ratio between arterial oxygen partial pressure and fraction of inspired oxygen $\left(\mathrm{PaO}_{2} / \mathrm{F}_{\mathrm{I}} \mathrm{O}_{2}\right)$ decreased from $454.0 \pm 67.4$ to $125.8 \pm 61.1(P<0.001)$. The respiratory rate in group $24 \mathrm{~h}$ was $19.8 \pm 2.4$ breaths per minute; $21.1 \pm 1.9$, in $48 \mathrm{~h} ; 23.0 \pm 1.9(P=0.026$ versus $24 \mathrm{~h}, P=0.008$ versus $72 \mathrm{~h}$ ) in $48 \mathrm{~h}$-ALI and $20.8 \pm 1.3 \mathrm{in} 72 \mathrm{~h}$. The tidal volume was $250.2 \pm 17.6 \mathrm{~mL}$ and did not vary among groups. As a result, the inspiratory flow in group $24 \mathrm{~h}, 48 \mathrm{~h}, 48 \mathrm{~h}-\mathrm{ALI}$, $72 \mathrm{~h}$ was $16.7 \pm 2.8,19.1 \pm 3.3,21.5 \pm 4.1(P<0.05$ versus $24 \mathrm{~h}$ and $72 \mathrm{~h}$ ) and $17.4 \pm 3.0 \mathrm{~L} / \mathrm{min}$, respectively. The worst static respiratory system elastance was found in the 48-ALI group $\left(58.6 \pm 12.9 \mathrm{~cm} \mathrm{H}_{2} \mathrm{O} / \mathrm{L}, P<0.05\right.$ versus all groups) in comparison with $44.6 \pm 7.2$ in group $24 \mathrm{~h}$, $46.8 \pm 3.9$ in $48 \mathrm{~h}$ and $48.9 \pm 6.4$ in group $72 \mathrm{~h}$.

\section{Pulmonary colonization and infections \\ Tracheobronchial colonization by $P$. aeruginosa}

As reported in Table 1, colonization of the tracheobronchial tree by P.aeruginosa was found in 11 out of the 16 animals (68.7\%) intubated with colonized ETTs. P.aeruginosa colonized 26 out of 198 samples (13.1\%). In particular, $8.9 \%$ of the samples from the right lung were colonized, in comparison with $9.7 \%$ from the left lung $(P=0.856)$. P.aeruginosa mostly colonized the trachea and main bronchi $(23.6 \%)$, and only $7.1 \%$ of the samples from the 

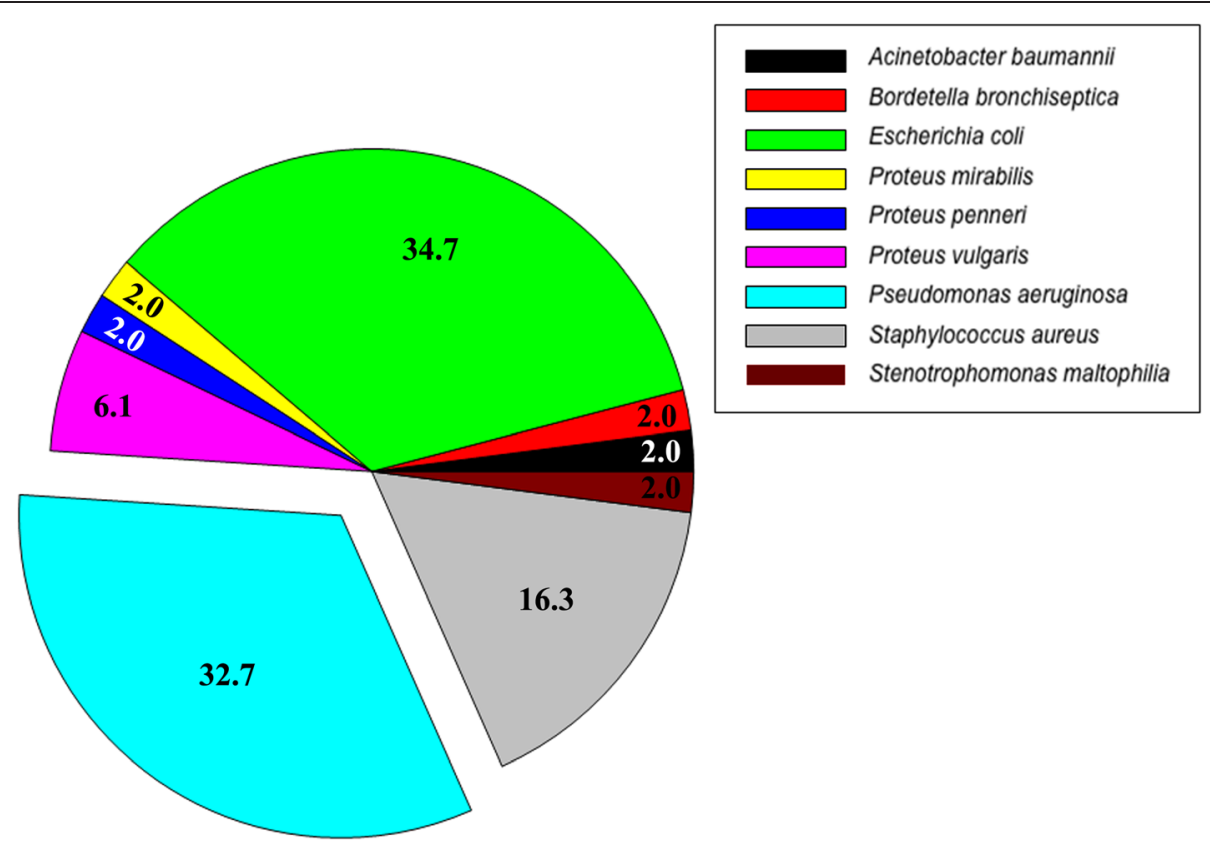

Figure 2 Endotracheal tube colonization. The pie chart represents the bacterial diversity recovered from the endotracheal tube upon extubation. The percentage of Pseudomonas aeruginosa isolates is explicitly indicated.

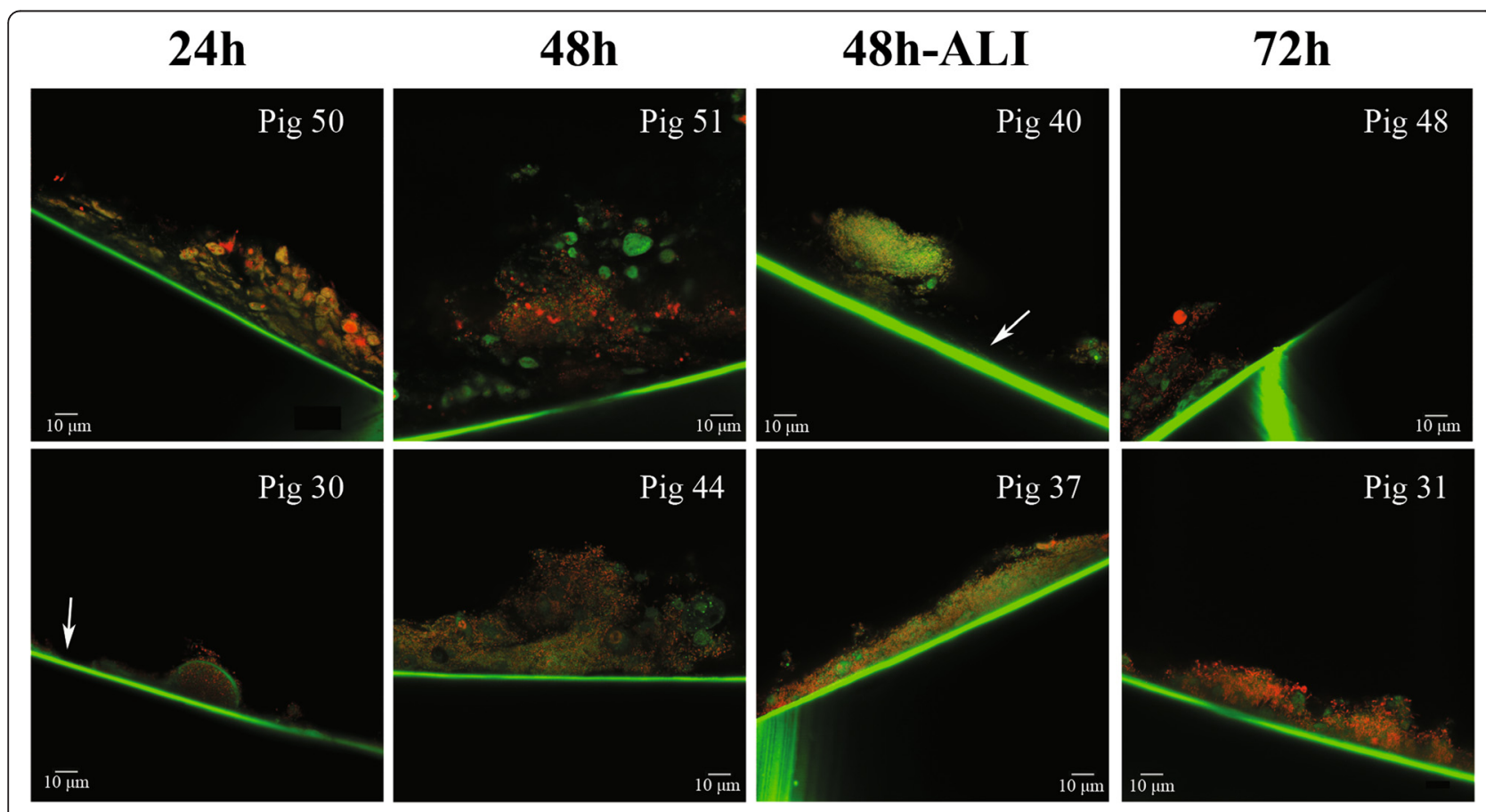

Figure 3 Confocal laser scanning micrograph of the internal surface of endotracheal tubes of animals mechanically ventilated for 24 , 48, 48 hours with concomitant lung injury and $\mathbf{7 2}$ hours. The samples were stained with BacLight Live/Dead (magnification $\times 250)$. The white arrow indicates the endotracheal tube internal surface. Note in all pictures a fully mature biofilm adherent to the endotracheal tube. 


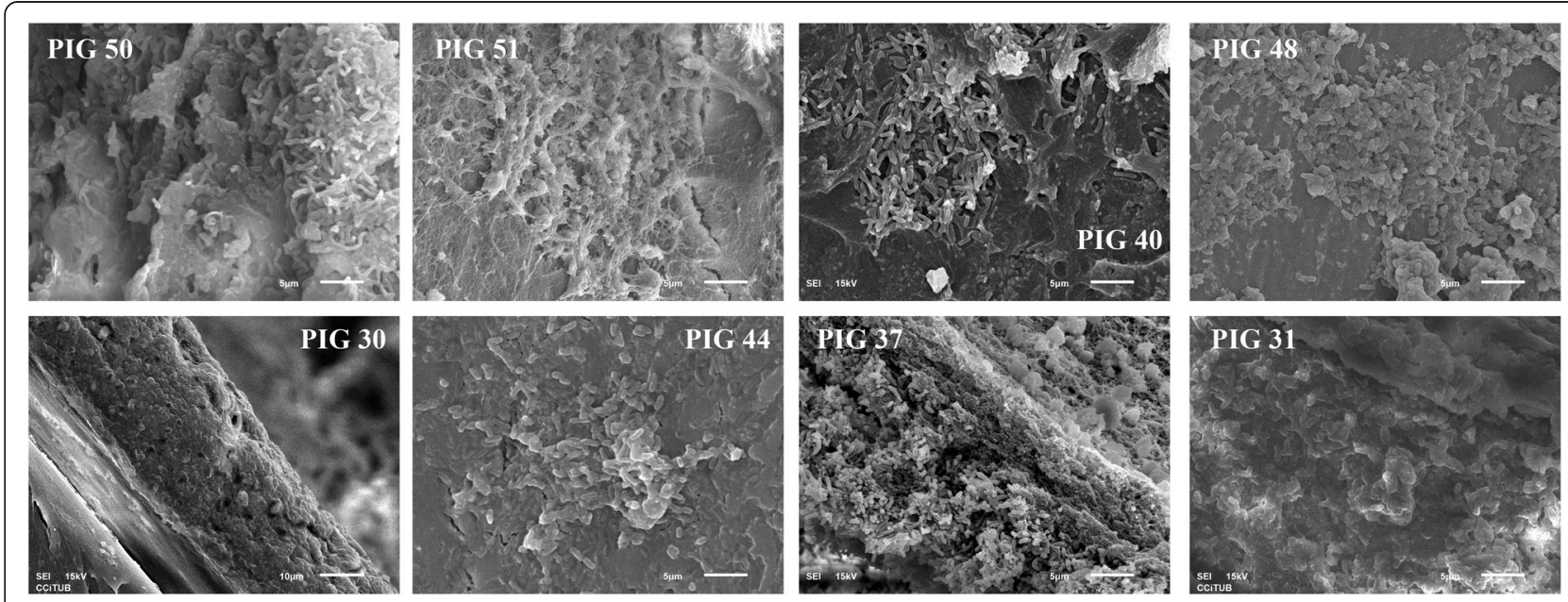

Figure 4 Scanning electron micrographs of the internal surface of the endotracheal tube (ETT) in animals mechanically ventilated for 24, 48, 48 hours with concomitant lung injury and $\mathbf{7 2}$ hours. Note in all pictures consistent presence of stage III/IV biofilm, characterized by multiple rod-shaped bacteria embedded within an extracellular polymeric substance. PIG 50, frontal view of the ETT lumen (magnification $\times 3,000$ ); PIG 30, cross-section of the ETT lumen (magnification × 1,500); PIG 51, frontal view of the ETT lumen (magnification $\times 3,000$ ); PIG 44, frontal-view of the ETT lumen (magnification $\times 3,000$ ); PIG 40, frontal view of the ETT lumen (magnification $\times 3,000$ ); PIG 37, frontal view of the ETT lumen (magnification $\times 3,000$ ); PIG 48, frontal view of the ETT lumen (magnification $\times 3,000$ ); PIG 31, frontal view of the ETT lumen (magnification $\times 3,000$ ).

segmental bronchi $(P=0.001)$. P.aeruginosa was found in $4.5 \%$ of the samples of group $24 \mathrm{~h}, 12.7 \%$ of group $48 \mathrm{~h}, 21.8 \%$ of group $48 \mathrm{~h}$-ALI and $11.4 \%$ of group $72 \mathrm{~h}$ $(P=0.085)$. The mean P.aeruginosa tracheobronchial concentration was $0.50 \pm 1.38 \mathrm{log} \mathrm{cfu} / \mathrm{g}$ and, as depicted in Figure 5A, only a trend toward higher colonization in group $48 \mathrm{~h}$-ALI was found $(P=0.059)$. The mean colonization of the trachea and main bronchi was $0.97 \pm 1.89 \mathrm{log}$ $\mathrm{cfu} / \mathrm{g}$, in comparison with $0.23 \pm 0.86$ of the segmental bronchi $(P<0.001)$. Post-hoc analyses confirmed that $P$.aeruginosa tracheobronchial concentration was not linearly associated with the length of stay on MV ( $r$-square: $0.010, P=0.222$ ). Conversely, post-hoc analysis of animals ventilated for $48 \mathrm{~h}$ showed that P.aeruginosa tracheobronchial concentration was higher in animals with pulmonary injury, versus no injury, $0.95 \pm 1.95$ and $0.32 \pm 1.03 \mathrm{log} \mathrm{cfu} / \mathrm{g}$, respectively $(P=0.016)$.

\section{Tracheobronchial colonization by other aerobic Gram-negative bacteria}

B. bronchiseptica was the most frequent pathogen, isolated in $75 \%$ of the colonized samples; $E$. coli was found in $19.2 \%$ samples, whereas Acinetobacter lwoffi, Acinetobacter baumanii and Paracoccus yeii were each isolated in $1.9 \%$ of the samples. E. coli colonized both the ETT and the tracheobronchial tree in five animals; whereas $B$. bronchiseptica only in one animal. Tracheal and main bronchi samples were more frequently colonized (36.1\% of the samples), in comparison with only $18.2 \%$ of the segmental bronchi samples $(P=0.005)$. In group $48 \mathrm{~h}$, $38.2 \%$ of the samples were colonized versus $11.4 \%$ in group $24 \mathrm{~h}$, and $20.4 \%$ in group $72 \mathrm{~h}(P=0.018)$. As reported in Figure 5B, the highest concentration of other aerobic Gram-negative bacteria was found in group $48 \mathrm{~h}$.

\section{Pulmonary infections}

Data on pulmonary infections are depicted in Table 2. Upon study completion respiratory infections were clinically suspected in 13 out of 18 animals (72.2\%). Incidence of clinically suspected pulmonary infections did not vary among groups. P.aeruginosa VAT was microbiologically confirmed in 5 out of 13 animals (38.5\%). Animals of group $24 \mathrm{~h}$ never developed respiratory infections, whereas $60 \%$ of the animals in group 48-ALI developed P.aeruginosa VAT. Among the animals with clinical suspicion of pulmonary infections, the right and left upper lobes were the sites most commonly sampled because of apparent gross findings of infection. Nevertheless, P.aeruginosa VAP was never microbiologically confirmed. As for pulmonary infections caused by other Gramnegative bacteria, VAT was microbiologically confirmed in five animals, mostly of group $48 \mathrm{~h}$-ALI (three out of five animals $(60 \%))$. VAP by other Gram-negative pathogens never developed. VAT was caused by B. bronchiseptica in $66.6 \%$ of the cases and E. coli in the remaining cases. In $50 \%$ of the cases of VAT, there was a concomitant isolation of P.aeruginosa and another Gram-negative pathogen.

\section{Discussion}

This laboratory animal study demonstrates that following intubation with an ETT colonized by mature P.aeruginosa biofilm, there is a consistent translocation of pathogens into the airways. Nevertheless, in animals on MV up to 72 hours and in LTP, the ETT biofilm only colonizes the 
Table 1 Tracheobronchial colonization (log cfu/g) per study group

\begin{tabular}{|c|c|c|c|c|c|c|c|c|c|c|c|c|c|c|}
\hline \multirow[b]{2}{*}{ Pig } & \multirow[b]{2}{*}{ Group } & \multirow[b]{2}{*}{ Mechanical ventilation, hours } & \multirow[b]{2}{*}{ Species } & \multicolumn{2}{|c|}{ Trachea } & \multicolumn{3}{|c|}{ Main bronchi } & \multicolumn{6}{|c|}{ Segmental bronchi } \\
\hline & & & & 1 & 2 & 3 & 4 & 5 & 6 & 7 & 8 & 9 & 10 & 11 \\
\hline 17 & $24 \mathrm{~h}$ & 24 & - & - & - & - & - & - & - & - & - & - & - & - \\
\hline \multirow[t]{2}{*}{20} & $24 \mathrm{~h}$ & 24 & P.aeruginosa & 2.18 & 2.74 & - & - & - & - & - & - & - & - & - \\
\hline & & & E.coli & 1.70 & 2.30 & - & - & - & - & - & - & - & - & - \\
\hline 30 & $24 \mathrm{~h}$ & 24 & Bordetella bronchiseptica & 2.90 & 3.85 & - & 5.09 & - & - & - & - & - & - & - \\
\hline 50 & $24 \mathrm{~h}$ & 24 & - & - & - & - & - & - & - & - & - & - & - & - \\
\hline 18 & $48 \mathrm{~h}$ & 48 & P.aeruginosa & 3.69 & 3.95 & 4.62 & 2.40 & - & - & 2.96 & - & - & - & - \\
\hline 27 & $48 \mathrm{~h}$ & 48 & Bordetella bronchiseptica & 6.19 & 7.24 & 7.14 & 7.37 & 5.76 & 5.16 & 5.99 & - & 3.70 & 3.66 & - \\
\hline \multirow[t]{4}{*}{44} & $48 \mathrm{~h}$ & 48 & P.aeruginosa & - & - & - & - & - & - & 2.95 & - & - & - & - \\
\hline & & & Bordetella bronchiseptica & - & 3.60 & - & 3.86 & 3.83 & - & 3.02 & - & - & - & - \\
\hline & & & E.coli & - & - & - & - & - & - & 2.88 & - & - & - & - \\
\hline & & & Acinetobacter baumanii & - & - & - & - & - & - & 3.08 & - & - & - & - \\
\hline 51 & $48 \mathrm{~h}$ & 48 & P.aeruginosa & - & - & - & 4.05 & - & - & - & - & - & - & - \\
\hline 55 & $48 \mathrm{~h}$ & 48 & Bordetella bronchiseptica & 5.56 & 4.60 & 5.33 & 7.12 & 5.76 & 4.63 & 5.72 & 2.30 & - & - & - \\
\hline \multirow[t]{2}{*}{34} & 48-ALI & 48 & P.aeruginosa & 4.68 & 5.02 & - & 6.41 & - & - & - & 4.24 & 4.18 & - & 3.85 \\
\hline & & & E.coli & 4.08 & - & - & - & - & - & - & - & - & - & - \\
\hline \multirow[t]{2}{*}{37} & 48-ALI & 48 & P.aeruginosa & 1.78 & - & - & - & - & - & - & - & - & - & - \\
\hline & & & Acinetobacter Iwoffii & - & - & - & - & - & - & - & - & - & - & 2.17 \\
\hline 40 & 48-ALI & 48 & P.aeruginosa & - & - & 3.21 & - & - & - & - & - & - & - & - \\
\hline \multirow[t]{2}{*}{52} & 48-ALI & 48 & P.aeruginosa & 6.86 & 2.95 & - & 5.86 & - & - & - & - & 3.76 & - & - \\
\hline & & & E.coli & 4.54 & 2.52 & - & - & - & - & - & - & - & - & - \\
\hline 54 & 48-ALI & 18 & Bordetella bronchiseptica & 3.80 & 3.12 & 3.23 & 3.32 & 2.18 & 3.09 & 3.11 & 2.40 & 3.26 & - & 2.75 \\
\hline \multirow[t]{3}{*}{22} & $72 \mathrm{~h}$ & 72 & P.aeruginosa & 4.64 & - & - & - & - & - & - & - & - & - & - \\
\hline & & & Bordetella bronchiseptica & 6.60 & 5.30 & - & 5.35 & 5.72 & - & - & - & 6.40 & - & - \\
\hline & & & Paracoccus yeei & - & - & - & - & - & - & - & - & - & 5.60 & - \\
\hline 31 & $72 \mathrm{~h}$ & 72 & - & - & - & - & - & - & - & - & - & - & - & - \\
\hline 48 & $72 \mathrm{~h}$ & 72 & P.aeruginosa & - & - & - & - & 1.77 & - & - & - & - & - & - \\
\hline \multirow[t]{2}{*}{53} & $72 \mathrm{~h}$ & 72 & P.aeruginosa & 4.86 & - & - & - & 3.45 & 2.08 & - & - & - & - & - \\
\hline & & & E.coli & 4.18 & - & - & - & 3.79 & 2.94 & - & - & - & - & - \\
\hline
\end{tabular}

Of note, bacterial species concurrently isolated from within the endotracheal tube and the tracheobronchial tree are in bold. P.aeruginosa, Pseudomonas aeruginosa; E.coli, Escherichia coli.

proximal airways and most importantly it does not cause VAP, even in injured lungs.

During MV, biofilm rapidly forms on the internal surface of ETTs [12,27]. ETT biofilm is a complex structure made of pathogens enclosed within a self-produced polymeric matrix, and respiratory secretions. The accumulation of biofilm and secretions within the ETT progressively obstructs its lumen, particularly in patients on long-term MV $[28,29]$. This increases the patient work of breathing and potentially delays liberation from MV [30]. The inspiratory flow interacts with the biofilm surface [31], which become unstable and eventually particles may be disseminated into the airways [12]. Additionally, ETT suctioning [32] or other invasive respiratory procedures, that is, bronchoscopy, may dislodge clumps of pathogens and biofilm elements.
Antibiotics do not eradicate ETT biofilm [33,34], and only dedicated devices have shown full removal of biofilm and secretions from within the ETT [35-37]. ETT biofilm plays a role in the development of VAP. Indeed, upon extubation in patients with VAP the internal ETT lumen is fully covered by airway secretions and pathogens within a thick biofilm [12,15,37]. Importantly these pathogens often match causative VAP microorganisms [12]. Therefore, several investigators have suggested that ETT biofilm might play a role in the development of VAP. To the best of our knowledge this is the first report that challenges this theory; indeed, we demonstrated that in pigs placed in the LTP, ETT biofilm is mostly associated with VAT rather than VAP.

In clinical settings, several preemptive interventions are applied to prevent VAT and VAP. Among those 

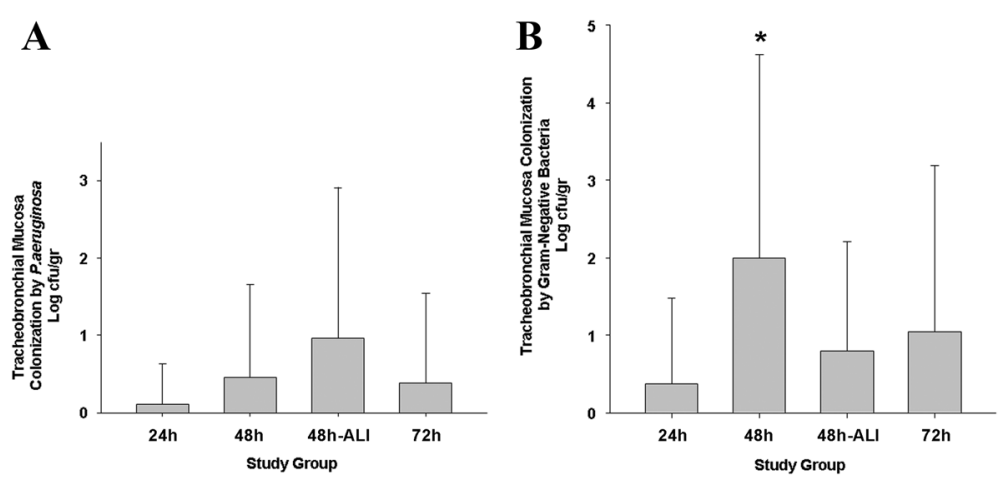

Figure 5 Tracheobronchial mucosa bacterial concentrations for P.aeruginos. (A) and all aerobic Gram-negative bacteria (B) per study group. The mean P.aeruginosa concentration did not differ among groups $(P=0.059)$, whereas, the concentration of all aerobic Gram-negative bacteria (B) was significantly different $(P=0.002)$. ${ }^{*} P=0.005$ versus group 24 h. 24 h, 24 hours; 48 h, 48 hours; 48 h-ALl, 48 hours with concomitant acute lung injury; $72 \mathrm{~h}, 72$ hours.

strategies international guidelines [38,39] strongly recommend that enterally fed patients on MV be kept in the semirecumbent position to prevent reflux of colonized gastric contents and the gastro-pulmonary route of colonization [1]. Yet results from laboratory studies [3-6] in large animals challenge the use of the semirecumbent position in patients with oropharyngeal colonization, because bacteria may be driven into the airways through gravity. In particular, studies in tracheally intubated pigs [4,5] and sheep [4] on MV for up to 168 hours report an incidence of VAP close to $95 \%$ in animals in the semirecumbent position. Conversely, mucus clearance was drastically improved and pulmonary infections fully prevented in animals positioned in the LTP.

In our study, we used ETTs already colonized by P.aeruginosa at the time of intubation, and the LTP. Therefore, it is rational to assume that P.aeruginosa disseminated only from within the ETT biofilm, and the concomitant inoculation of endogenous oropharyngeal pathogens was limited because of the position and prophylactic antibiotic therapy with ceftriaxone. Importantly, colonized ETTs were obtained from a previous study [3] in which animals underwent MV for 72 hours and presented oropharyngeal colonization by P.aeruginosa. Thus, in the current study, we used ETTs with late-stage biofilm formation. Interestingly, colonization by P.aeruginosa was not corroborated in 2 out of 18 ETTs. This was likely related to the bacterial diversity and complex ecology of the studied ETTs and the vast presence of microbial competitors, that is, $P$. vulgaris, B. bronchiseptica, E.coli and S. aureus. In a previous canine model of ETT biofilm-associated pulmonary infection [17], the investigators challenged the oropharynx with P.aeruginosa. This led to aspiration of colonized secretion into the airways, extensive biofilm formation within the ETT and ultimately to VAP. Although this model closely simulated the pathogenic mechanisms of VAP in clinical settings, it was impossible to differentiate between the role of ETT and oropharyngeal colonization in the development of the infection. Consequently, this is the first study that substantiates a preventive effect of the LTP in the development of pulmonary infections specifically caused by ETT biofilm. Other important features of our model were the complete absence of PEEP [40] and the development of lung injury $[41,42]$ in one of the groups. These settings were specifically employed to replicate the worst possible clinical conditions for the development of respiratory infections during MV. According to previous studies [17] extensive biofilm formation is found in all ETTs. Nevertheless, we also found a trend toward higher ETT colonization in group 48-ALI and 72-h. These animals were at greater risk of VAP because of lung injury and prolonged time on $\mathrm{MV}$; thus, this imbalance between groups further validates the benefits of the LTP. Yet we found slightly enhanced pulmonary colonization in group 48-ALI. This could be explained by the impairment of the host immune response, due to the lung injury and the ventilatory settings. Indeed, in these animals the respiratory rate was greater to maintain normocapnia, and as a result higher inspiratory airflow was generated. This could have led to flow turbulence within the ETT and substantial dislodgement of biofilm particles.

This study has a few limitations that need to be highlighted. First, ETT colonized by P.aeruginosa were employed, hence our results may not be valid for other bacterial species. Second, although we did not find a progressive increase in risk of pulmonary colonization associated with the time on MV, the animals were ventilated for up to 72 hours and our results may not be relevant during prolonged time on MV. Third, we found a concomitant colonization by endogenous pathogens, namely, B. bronchiseptica and E. coli in a few animals. This could have caused active competition for colonization, and led to decreased risk of P.aeruginosa colonization. Additionally, in the current and the associated study, 


\begin{tabular}{|c|c|c|c|c|c|c|c|c|c|c|c|}
\hline \multirow[b]{2}{*}{ Pig } & \multirow[b]{2}{*}{ Group } & \multirow[b]{2}{*}{$\begin{array}{l}\text { Hours } \\
\text { of } M V\end{array}$} & \multirow[b]{2}{*}{ Fever ${ }^{*}\left({ }^{\circ} \mathrm{C}\right)$} & \multirow[b]{2}{*}{$\begin{array}{l}\text { WBC* } \\
\text { (cells/mm3) }\end{array}$} & \multirow[b]{2}{*}{$\begin{array}{l}\text { Purulent } \\
\text { secretions* }\end{array}$} & \multirow[b]{2}{*}{$\begin{array}{l}\text { Clinical suspicion } \\
\text { of VAP/VAT }\end{array}$} & \multicolumn{2}{|c|}{ Pseudomonas Aeruginosa } & \multicolumn{3}{|c|}{ Gram-negative bacteria } \\
\hline & & & & & & & $\begin{array}{l}\text { Microbiologically } \\
\text { confirmed VAP }\end{array}$ & $\begin{array}{l}\text { Microbiologically } \\
\text { confirmed VAT }\end{array}$ & $\begin{array}{l}\text { Microbiologically } \\
\text { confirmed VAP }\end{array}$ & Species & $\begin{array}{l}\text { Microbiologically } \\
\text { confirmed VAT } \\
\end{array}$ \\
\hline 17 & $24 \mathrm{~h}$ & 24 & 37.6 & 21400 & No & No & No & No & No & - & No \\
\hline 20 & $24 \mathrm{~h}$ & 24 & 40.2 & 23100 & No & Yes & No & No & No & - & No \\
\hline 30 & $24 \mathrm{~h}$ & 24 & 38.5 & 19700 & No & Yes & No & No & No & - & No \\
\hline 50 & $24 \mathrm{~h}$ & 24 & 37.4 & 39500 & Yes & Yes & No & No & No & - & No \\
\hline 18 & $48 \mathrm{~h}$ & 48 & 39.2 & 20500 & No & Yes & No & Yes & No & - & No \\
\hline 27 & $48 \mathrm{~h}$ & 48 & 38.3 & 28000 & No & No & No & No & No & - & No \\
\hline 44 & $48 \mathrm{~h}$ & 48 & 36.2 & 21700 & Yes & Yes & No & No & No & Bordetella bronchiseptica & Yes \\
\hline 51 & $48 \mathrm{~h}$ & 48 & 37.6 & 18200 & No & No & No & No & No & - & No \\
\hline 55 & $48 \mathrm{~h}$ & 48 & 36.1 & 18300 & Yes & Yes & No & No & No & Bordetella bronchiseptica & Yes \\
\hline 34 & 48-ALI & 48 & 36.0 & 16400 & Yes & Yes & No & Yes & No & Escherichia coli & Yes \\
\hline 37 & 48-ALI & 48 & NA & 21600 & Yes & Yes & No & No & No & - & No \\
\hline 40 & 48-ALI & 48 & 38.9 & 29000 & Yes & Yes & No & Yes & No & - & No \\
\hline 52 & 48-ALI & 48 & 37.6 & 24900 & Yes & Yes & No & Yes & No & Escherichia coli & Yes \\
\hline 54 & 48-ALI & 18 & NA & 24700 & Yes & Yes & No & No & No & Bordetella bronchiseptica & Yes \\
\hline 22 & $72 \mathrm{~h}$ & 72 & NA & 18600 & Yes & Yes & No & Yes & No & Bordetella bronchiseptica & Yes \\
\hline 31 & $72 \mathrm{~h}$ & 72 & 36.0 & 22000 & Yes & Yes & No & No & No & - & No \\
\hline 48 & $72 \mathrm{~h}$ & 72 & 37.0 & 22700 & No & No & No & No & No & - & No \\
\hline 53 & $72 \mathrm{~h}$ & 72 & 36.5 & 21700 & No & No & No & No & No & - & No \\
\hline
\end{tabular}

Pulmonary infections were clinically suspected in the case of at least two of three of the following clinical features: body temperature $>38.5^{\circ} \mathrm{C}$ or $<36^{\circ} \mathrm{C}$; white blood count $>14,000 / \mathrm{mm}^{3}$ or $<4,000 / \mathrm{mm} \mathrm{m}^{3}$ and purulent secretions. VAT was microbiologically confirmed when a bronchial mucosa culture was $\geq 3 \log \mathrm{cfu} / \mathrm{g}$. VAP was microbiologically confirmed according to a lung tissue quantitative bacterial culture $\geq 3$ log cfu/g. Of note, only pulmonary lobes with apparent gross findings of pneumonia (edematous tissue; consolidated areas; mucopurulent material in the tracheobronchial tree; abscess) were sampled, whereas in group 48-ALI all lobes were sampled. *Only values upon autopsy are reported in the table, but statistical analysis included all values collected every 12 hours: $P$-values for differences among groups were 0.212 (Fever), 0.276 (WBC), 0.298 (Purulent secretions), 0.439 (Clinical suspicion of VAPNAT), not significant (Microbiologically confirmed VAP) and 0.327 (Microbiologically confirmed VAT) for $P$. Aeruginosa, and not significant (Microbiologically confirmed VAP) and 0.423 (Microbiologically confirmed VAT) for Gram-negative bacteria. ALI, acute lung injury; MV, mechanical ventilation; VAP, ventilator-associated pneumonia; VAT, ventilator associated tracheobronchitis; WBC, white blood cell; 24 h, 24 hours; 48 h, 48 hours; 48 h-ALI, 48 hours with concomitant acute lung injury; 72 h, 72 hours. 
microbiology samples of the oropharynx and gastric contents were not collected, thus, the specific origin of bacteria colonizing the ETTs remains uncertain. Fourth, in the present study, we did not test whether the semirecumbent position could further promote biofilm-associated pulmonary infections. Yet several of our previous studies $[3,6,18]$ confirmed that such a position consistently caused pulmonary infections through gravity-driven aspiration of oropharyngeal contents, and likely through translocation of ETT pathogens. Last, although sample size analysis indicated that three animals per group would be sufficient to demonstrate our goals, larger laboratory and clinical studies should validate our results. Nevertheless, it is important to emphasize that we did not find any trend toward an increased risk of VAP associated with the length of stay on MV and lung injury.

\section{Conclusions}

In summary, this animal study implies that during the course of invasive MV, P.aeruginosa biofilm within the ETT rapidly colonizes the proximal respiratory tract. Nevertheless, when animals are positioned in the LTP, bacterial colonization is compartmentalized within the proximal airways and during the first 72 hours of MV plays a marginal role in the development of VAP.

\section{Key messages}

- Following intubation with an endotracheal tube colonized by mature $P$. aeruginosa biofilm, there is a consistent translocation of pathogens into the airways.

- In animals positioned in the lateral Trendelenburg position and mechanically ventilated for up to 72 hours, endotracheal tube $P$. aeruginosa biofilm mostly colonizes the trachea and main bronchi

- However, in the lateral Trendelenburg position, endotracheal tube $P$. aeruginosa biofilm only causes ventilator-associated tracheobronchitis.

- Lung injury marginally increases risks of endotracheal tube $P$. aeruginosa biofilm pulmonary colonization and infection.

\footnotetext{
Abbreviations

ALl: acute lung injury; cfu/g: colony forming units per gram; CSLM: confocal scanning laser microscopy; ETT: endotracheal tube; LTP: lateral-Trendelenburg position; MV: mechanical ventilation; PEEP: positive end-expiratory pressure; SEM: scanning electron microscopy; VAP: ventilator-associated pneumonia; VAT: ventilator-associated tracheobronchitis.
}

\section{Competing interests}

Outside the submitted work, Antoni Torres and Gianluigi Li Bassi received, through their institution, research funds by Biovo Ltd., the manufacturer of the Airway Medix Closed Suctioning System for the removal of endotracheal tube biofilm. Additionally, Gianluigi Li Bassi receives royalties through the National Institutes of Health, Bethesda, MD for the Mucus Slurper patent, a novel endotracheal tube that prevents biofilm formation. All the remaining authors do not have any competing interest associated with the submitted work.

\section{Authors' contributions}

GLB and LF had full access to all of the data in the study and take responsibility for the integrity of the data and the accuracy of the data analysis. Study concept and design: $G L B, L F, L S, M F$, JV, and AT; acquisition of data: GLB, LF, LS, VG, OTR, EAX, JDM, IR, LM, MR, NL, ME, MAS, and JR; analysis and interpretation of data: GLB, LF and EAX; drafting of the manuscript: GLB and LF; critical revision of the manuscript for important intellectual content: MF, JR, JV, and AT; statistical analysis: GLB; administrative, technical, or material support: LF, IR, and LM. All authors read and approved the manuscript.

\section{Acknowledgements}

We thank the Institut d'Investigacions Biomèdiques August Pi i Sunyer (IDIBAPS), Ministerio de Ciencia e Innovación (PS09/01249); European Society of Intensive Care Medicine-ESICM (2009 Alain Harf Award on Applied Respiratory Physiology); Fundació Catalana de Pneumologıa (FUCAP); Sociedad Española de Neumología y Cirugía Torácica (SEPAR); Centro de Investigación Biomedica En Red-Enfermedades Respiratorias, (CIBERES) for their financial support to carry out the study. Importantly, all aforementioned funding bodies did not play any role in the design, collection, analysis, or interpretation of data; in the writing of the manuscript; or in the decision to submit the manuscript for publication. We also acknowledge the members of the Animal Experimentation Ethics Committee of the University of Barcelona for their evaluation and approval of our study protocol: Dr Jordi Alberch Vie; Álvaro Gimeno Sandig; Raquel Corral Vistué; Dr Garikoitz Azkona Mendoza; Dr Victor Fernández Dueñas; Dr Jordi Guinea Mejías; Dr Francesc López Soriano; Dr Carmen Navarro Aragay; Dr Francisco José Pérez Can; Dr Montserrat Rigol Muixart and Dr Teresa Rodrigo Calduch.

\section{Author details}

'Pulmonary and Critical Care Unit, Hospital Clínic, Calle Villarroel 170, Esc 6/8 Planta 2, 08036 Barcelona, Spain. ${ }^{2}$ Institut d'Investigacions Biomèdiques August Pi i Sunyer (IDIBAPS), Barcelona, Spain. ${ }^{3}$ Centro de Investigación Biomedica En Red- Enfermedades Respiratorias (CIBERES), Mallorca, Spain. ${ }^{4}$ University of Milan, Milan, Italy. ${ }^{5}$ Hospital das Clínicas, Faculdade de Medicina da Universidade de São Paulo, Pulmonary Intensive Care Unit, São Paulo, Brazil. ${ }^{6}$ Department of Clinical Microbiology, School of Medicine, and Barcelona Centre for International Health Research, (CRESIB) Hospital Clínic, Universitat de Barcelona, Barcelona, Spain. 'Pathology Department, Hospital Clinic, Barcelona, Spain. ${ }^{8}$ University of Barcelona, Barcelona, Spain.

Received: 14 October 2014 Accepted: 3 February 2015

Published online: 27 February 2015

\section{References}

1. Torres A, Serra-Batlles J, Ros E, Piera C, Puig de la Bellacasa J, Cobos A, et al. Pulmonary aspiration of gastric contents in patients receiving mechanical ventilation: the effect of body position. Ann Intern Med. 1992;116:540-3.

2. Drakulovic MB, Torres A, Bauer TT, Nicolas JM, Nogué S, Ferrer M. Supine body position as a risk factor for nosocomial pneumonia in mechanically ventilated patients: a randomised trial. Lancet. 1999;354:1851-8.

3. Li Bassi G, Marti JD, Saucedo L, Rigol M, Roca I, Cabanas M, et al. Gravity predominates over ventilatory pattern in the prevention of ventilator-associated pneumonia. Crit Care Med. 2014;42:e620-7.

4. Panigada M, Berra L, Greco G, Stylianou M, Kolobow T. Bacterial colonization of the respiratory tract following tracheal intubation-effect of gravity: an experimental study. Crit Care Med. 2003:31:729-37.

5. Zanella A, Cressoni M, Epp M, Hoffmann V, Stylianou M, Kolobow T. Effects of tracheal orientation on development of ventilator-associated pneumonia: an experimental study. Intensive Care Med. 2012;38:677-85.

6. Li Bassi G, Zanella A, Cressoni M, Stylianou M, Kolobow T. Following trachea intubation, mucus flow is reversed in the semirecumbent position: possible role in the pathogenesis of ventilator-associated pneumonia. Crit Care Med. 2008;36:518-25.

7. Costerton JW, Stewart PS, Greenberg EP. Bacterial biofilms: a common cause of persistent infections. Science. 1999:284:1318-22.

8. Flemming HC, Neu TR, Wozniak DJ. The EPS matrix: the "house of biofilm cells". J Bacteriol. 2007:189:7945-7.

9. Høiby N, Bjarnsholt T, Givskov M, Molin S, Ciofu O. Antibiotic resistance of bacterial biofilms. Int J Antimicrob Agents. 2010;35:322-32.

10. Jensen $P \varnothing$, Givskov M, Bjarnsholt T, Moser $C$. The immune system vs Pseudomonas aeruginosa biofilms. FEMS Immunol Med Microbiol. 2010;59:292-305 
11. Gil-Perotin S, Ramirez P, Marti V, Sahuquillo JM, Gonzalez E, Calleja I, et al. Implications of endotracheal tube biofilm in ventilator-associated pneumonia response: a state of concept. Crit Care. 2012;16:R93.

12. Adair CG, Gorman SP, Feron BM, Byers LM, Jones DS, Goldsmith CE, et al. Implications of endotracheal tube biofilm for ventilator-associated pneumonia. Intensive Care Med. 1999:25:1072-6.

13. Inglis TJ, Millar MR, Jones JG, Robinson DA. Tracheal tube biofilm as a source of bacterial colonization of the lung. J Clin Microbiol. 1989:27:2014-8.

14. Sottile FD, Marrie TJ, Prough DS, Hobgood CD, Gower DJ, Webb LX, et al. Nosocomial pulmonary infection: possible etiologic significance of bacterial adhesion to endotracheal tubes. Crit Care Med. 1986;14:265-70.

15. Wilson A, Gray D, Karakiozis J, Thomas J. Advanced endotracheal tube biofilm stage, not duration of intubation, is related to pneumonia. J Trauma Acute Care Surg. 2012;72:916-23.

16. Committee for the Update of the Guide for the Care and Use of Laboratory Animals. Guide for the care and use of laboratory animals. Washington, DC: National Academies Press; 2011.

17. Olson ME, Harmon BG, Kollef MH. Silver-coated endotracheal tubes associated with reduced bacterial burden in the lungs of mechanically ventilated dogs. Chest. 2002;121:863-70

18. Li Bassi G, Rigol M, Marti JD, Saucedo L, Ranzani OT, Roca I, et al. A novel porcine model of ventilator-associated pneumonia caused by oropharyngeal challenge with Pseudomonas aeruginosa. Anesthesiology. 2014;120(5):1205-15.

19. Farré $R$, Rotger $M$, Ferre $M$, Torres $A$, Navajas D. Automatic regulation of the cuff pressure in endotracheally-intubated patients. Eur Respir J. 2002;20:1010-3.

20. Pelosi P, Goldner M, McKibben A, Adams A, Eccher G, Caironi P, et al. Recruitment and derecruitment during acute respiratory failure: An experimental study. Am J Respir Crit Care Med. 2001;164:122-30.

21. Li Bassi G, Saucedo L, Marti JD, Rigol M, Esperatti M, Luque N, et al. Effects of duty cycle and positive end-expiratory pressure on mucus clearance during mechanical ventilation*. Crit Care Med. 2012;40:895-902.

22. Demirev PA, Ho YP, Ryzhov V, Fenselau C. Microorganism identification by mass spectrometry and protein database searches. Anal Chem. 1999;71:2732-8.

23. Rouby JJ, Martin De Lassale E, Poete P, Nicolas MH, Bodin L, Jarlier V, et al. Nosocomial bronchopneumonia in the critically ill. Histologic and bacteriologic aspects. Am Rev Respir Dis. 1992;146:1059-66.

24. Luna CM, Baquero S, Gando S, Patrón JR, Morato JG, Sibila O, et al. Experimental severe Pseudomonas aeruginosa pneumonia and antibiotic therapy in piglets receiving mechanical ventilation. Chest. 2007;132:523-31.

25. Fernández-Barat L, Ferrer M, Sierra JM, Soy D, Guerrero L, Vila J, et al. Linezolid limits burden of methicillin-resistant Staphylococcus aureus in biofilm of tracheal tubes. Crit Care Med. 2012;40:2385-9.

26. Fernández-Barat L, Li Bassi G, Ferrer M, Bosch A, Calvo M, Vila J, et al. Direct analysis of bacterial viability in endotracheal tube biofilm from a pig model of methicillin-resistant Staphylococcus aureus pneumonia following antimicrobial therapy. FEMS Immunol Med Microbiol. 2012;65:309-17.

27. Berra L, De Marchi L, Yu ZX, Laquerriere P, Baccarelli A, Kolobow T. Endotracheal tubes coated with antiseptics decrease bacterial colonization of the ventilator circuits, lungs, and endotracheal tube. Anesthesiology. 2004;100:1446-56.

28. Inglis TJ, Lim TM, Ng ML, Tang EK, Hui KP. Structural features of tracheal tube biofilm formed during prolonged mechanical ventilation. Chest. 1995;108:1049-52.

29. Shah $\mathrm{C}$, Kollef $\mathrm{MH}$. Endotracheal tube intraluminal volume loss among mechanically ventilated patients. Crit Care Med. 2004;32:120-5.

30. Rumbak MJ, Walsh FW, Anderson WM, Rolfe MW, Solomon DA. Significant tracheal obstruction causing failure to wean in patients requiring prolonged mechanical ventilation: a forgotten complication of long-term mechanical ventilation. Chest. 1999;115:1092-5.

31. Inglis TJ. Evidence for dynamic phenomena in residual tracheal tube biofilm. Br J Anaesth. 1993;70:22-4.

32. Ng KS, Kumarasinghe $G$, Inglis TJ. Dissemination of respiratory secretions during tracheal tube suctioning in an intensive care unit. Ann Acad Med Singapore. 1999;28:178-82.

33. Adair CG, Gorman SP, Byers LM, Jones DS, Feron B, Crowe M, et al. Eradication of endotracheal tube biofilm by nebulised gentamicin. Intensive Care Med. 2002;28:426-31.

34. Adair CG, Gorman SP, O'Neill FB, McClurg B, Goldsmith EC, Webb CH. Selective decontamination of the digestive tract (SDD) does not prevent the formation of microbial biofilms on endotracheal tubes. J Antimicrob Chemother. 1993;31:689-97.

35. Liu W, Zuo Z, Ma R, Zhang X. Effect of mechanical cleaning of endotracheal tubes with sterile urethral catheters to reduce biofilm formation in ventilator patients. Pediatr Crit Care Med. 2013;14:e338-43.

36. Mietto C, Foley K, Salerno L, Oleksak J, Pinciroli R, Goverman J, et al. Removal of endotracheal tube debris obstruction with a secretion clearing device. Respir Care. 2013;59(9):e122-6.

37. Berra L, Coppadoro A, Bittner EA, Kolobow T, Laquerriere P, Pohlmann JR, et al. A clinical assessment of the Mucus Shaver: a device to keep the endotracheal tube free from secretions*. Crit Care Med. 2012;40:119-24.

38. Rello J, Lode H, Cornaglia G, Masterton R, VAP Care Bundle Contributors. A European care bundle for prevention of ventilator-associated pneumonia. Intensive Care Med. 2010;36:773-80

39. Infectious Diseases Society of America. Guidelines for the management of adults with hospital-acquired, ventilator-associated, and healthcare-associated pneumonia. Am J Respir Crit Care Med. 2005;171:388-416.

40. Manzano F, Fernández-Mondéjar E, Colmenero M, Poyatos ME, Rivera R, Machado J, et al. Positive-end expiratory pressure reduces incidence of ventilator-associated pneumonia in nonhypoxemic patients. Crit Care Med. 2008:36:2225-31.

41. Markowicz P, Wolff M, Djedaïni K, Cohen Y, Chastre J, Delclaux C, et al. Multicenter prospective study of ventilator-associated pneumonia during acute respiratory distress syndrome. Incidence, prognosis, and risk factors. ARDS Study Group. Am J Respir Crit Care Med. 2000;161:1942-8.

42. Chastre J, Trouillet JL, Vuagnat A, Joly-Guillou ML, Clavier H, Dombret MC, et al. Nosocomial pneumonia in patients with acute respiratory distress syndrome. Am J Respir Crit Care Med. 1998;157:1165-72.

\section{Submit your next manuscript to BioMed Central and take full advantage of:}

- Convenient online submission

- Thorough peer review

- No space constraints or color figure charges

- Immediate publication on acceptance

- Inclusion in PubMed, CAS, Scopus and Google Scholar

- Research which is freely available for redistribution 